\title{
Primary chest wall chondrosarcoma presenting as a breast
}

\section{mass}

\author{
Geetika Arora Klevos ${ }^{1}$, Margaret Cookson ${ }^{2 *}$, Gregory Foremny ${ }^{3}$, Khaled J Algashaamy ${ }^{4}$ and Monica M Yepes ${ }^{1}$ \\ ${ }^{1}$ Department of Radiology, Breast Imaging, University of Miami, Fl, USA \\ ${ }^{2}$ Herbert Wertheim College of Medicine, Florida International University, Miami Fl, USA \\ ${ }^{3}$ Department of Radiology, Jackson Memorial Hospital, University of Miami, Fl, USA \\ ${ }^{4}$ Department of Pathology, University of Miami, Fl, USA
}

\begin{abstract}
Chondrosarcomas are rare malignant neoplasms of chondroid matrix that commonly present with pain or as a palpable mass. When chondrosarcomas affect the rib, it is possible that patients present with a growing breast mass, although this has not been frequently reported. We present the case of a 46-year-old female complaining of an enlarging painless palpable mass of the right breast, which was diagnosed as chondrosarcoma after radiographic and pathologic workup. To our knowledge, primary chest wall chondrosarcomas presenting as a breast mass seen on mammogram has not been reported to date. It is important for radiologists to understand the imaging findings of chondrosarcoma, as these rare tumors can present in many ways.
\end{abstract}

\section{Introduction}

Chondrosarcoma is a malignant neoplasm that produces a chondroid matrix with primary chondrosarcomas arising de novo and secondary chondrosarcomas developing in pre-existing benign lesions $[1,2]$. Chondrosarcomas are the most common malignant chest wall tumors [3] and third most common primary bone malignancy following multiple myeloma and osteosarcoma [4]. Despite an incidence of less than 0.5 cases per million people per year, chondrosarcoma is the most frequent malignant tumor of the thoracic cage [5]. While most primary chest wall chondrosarcomas are thought to arise de novo, as many as $10 \%$ are contributed to radiation exposure from treatment of previous malignancies, including breast cancer and lymphoma [6,7]. We present the case of a 46-year-old female presenting with an enlarging painless palpable mass of the right breast that was diagnosed as a chondrosarcoma after workup.

\section{Case report}

A 46-year-old female with no personal or family history of cancer presented with a painless palpable mass of the right breast, which she stated had progressively increased in size over the last three years. Physical examination revealed a firm, immobile, deep seated, grossly visible mass over the right breast measuring approximately $15 \times 15 \mathrm{~cm}$. There was no associated tenderness, discoloration or retraction of the overlying skin (Figure 1).

Digital diagnostic mammography demonstrated a retropectoral right breast mass with central calcifications in an arc and ring configuration (Figure 2). Ultrasound revealed a $16 \mathrm{~cm}$ heterogenous cystic and solid mass (Figure 3). Ultrasound guided core needle biopsy was performed. Microscopic examination of the slides demonstrated large amounts of chondroid matrix with areas of myxoid changes. The chondrocytes demonstrate mild nuclear pleomorphism with rare mitoses, occasional multinucleated forms are also available, areas of cluster formation by chondrocytes some of which appear to be swollen as a result of cytoplasmic vacuolization. As per the pathologic findings described above this tumor is considered a grade 2, conventional chondrosarcoma (Figure 4). CT was then obtained to define the extent of the tumor for preoperative planning and revealed a multilobulated septate $15 \times 14.5 \times 10 \mathrm{~cm}$ mass with several central scattered punctate mineralization's arising from the anterolateral segment of the right fifth rib (Figure 5). MRI showed a large lobular T2 hyperintense mass arising from the anterior aspect of the right fifth rib invading the overlying pectoralis major muscle. Extension through the intercostal muscles into the anterior chest wall between the second through sixth ribs was also noted. Postcontrast MRI images demonstrated extensive septal enhancement, consistent with underlying chondroid matrix (Figure 6).

The patient was referred for surgical management and successfully underwent a right mastectomy and right radical chest wall resection

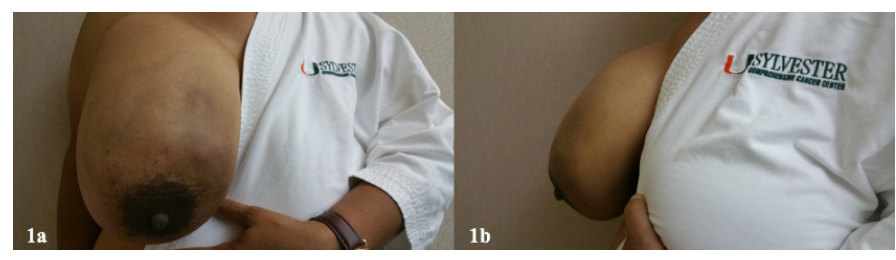

Figure 1. 46-year-old female with conventional primary chondrosarcoma of the right fifth rib. A) Frontal view of the patient's right breast. B) Lateral view of the patient's right breast.

Correspondence to: Margaret Cookson, Herbert Wertheim College of Medicine, Florida International University, Miami Fl, USA; E-mail: margaret.t.cookson@ gmail.com

Key words: Chondrosarcoma, breast mass, mammogram, computer tomography, ultrasound, magnetic resonance imaging

Received: October 02, 2017; Accepted: October 27, 2017; Published: October 30,2017 


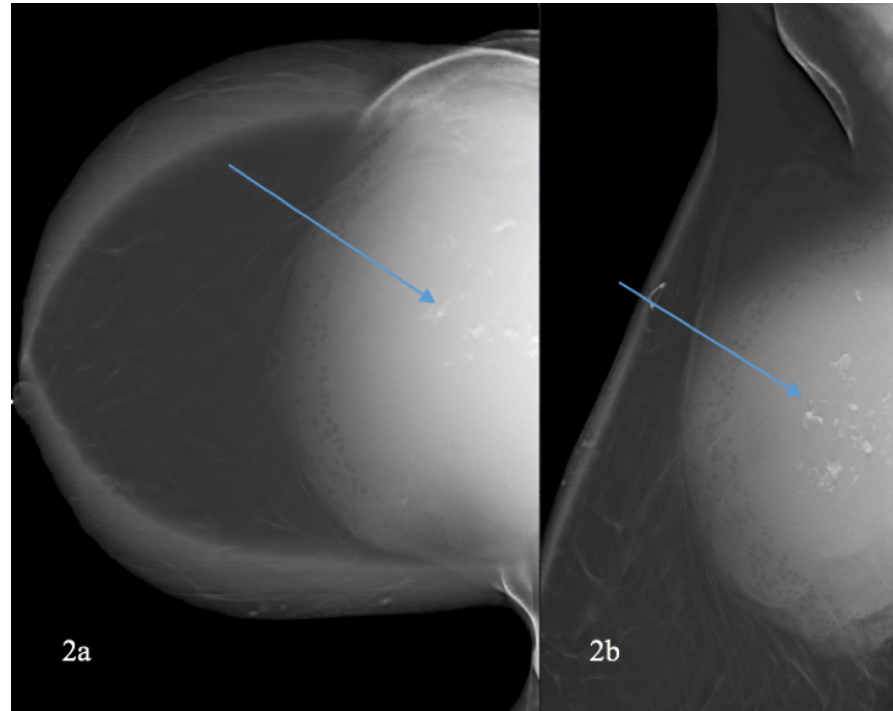

Figure 2. A) Cranio Caudal (CC) mammographic view of the right breast. Demonstrates a retropectoral mass with central calcifications (blue arrow), corresponding to the area of palpable abnormality. B) Medio Lateral Oblique (MLO) mammographic view of the right breast. Demonstrates a retropectoral mass with central calcifications in a ring and arc pattern (blue arrow), corresponding to the area of palpable abnormality.Technique. Digital diagnostic CC and MLO views of bilateral breast were obtained with tomosysnthesis. CAD was utilized.

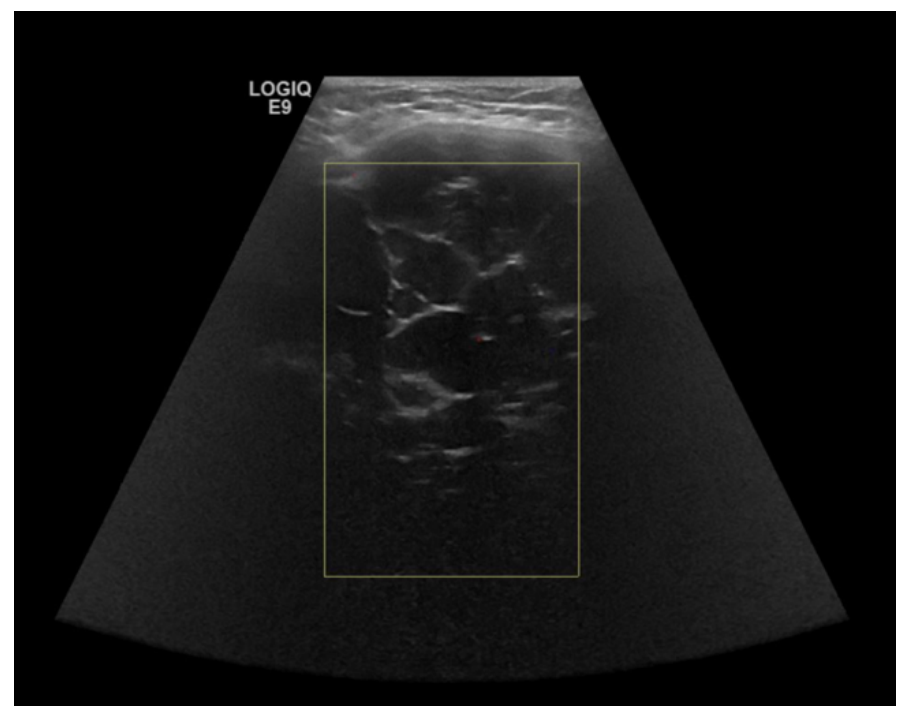

Figure 3. Real time sonography of the upper inner right breast with color doppler using an anti-radial approach. Demonstrates a retropectoral chest wall mass corresponding to the area of palpable abnormality, multiple nonvascular cystic areas demonstrated, as outlined by the yellow doppler box.Technique. Real-time hand-held multiplanar high resolution grey scale imaging of right breast and axilla was performed using a Linear 6-15 $\mathrm{MHz}$ transducer with select Doppler imaging as needed.

of the 3rd through 6 th ribs with negative resection margins. On final pathology the tumor was found to arise from the surface of the costal cartilages and adjacent ribs and was found to invade the medullary cavity of the fifth rib. No lymph node or vascular invasion was identified. The tumor was confined by the pectoralis muscle with no invasion of the overlying mammary parenchyma. An incidental finding of DCIS intermediate nuclear grade DIN 2 was found in the lower outer quadrant of the right mastectomy specimen. The DCIS was greater than $1 \mathrm{~cm}$ from the closest parenchymal resection margin. No invasive component was identified.

\section{Discussion}

\section{Clinical and imaging findings}

Conventional primary chondrosarcomas commonly present as pain or a palpable soft tissue mass in the 4th and 5th decade of life and demonstrate a slight male predominance $[2,3]$. They frequently present in long tubular bones, most commonly in the femur with the rib

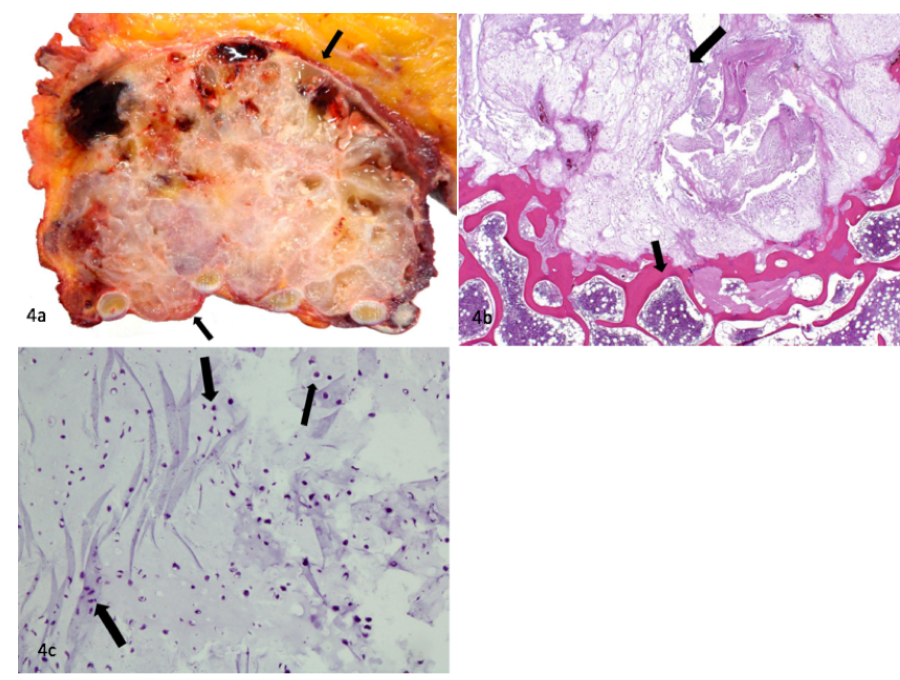

Figure 4. A) Gross photo showing a tan variegated locular well circumscribed lesion with focal areas of hemorrhage, emanating from the rib and abutting the overlying breast tissue.B) Low power view demonstrating a chondroid matrix containing a population of atypical pleomorphic chondrocytes. It also shows underlying bone with normal hematopoetic trilineage. C) High power view, demonstrating mild nuclear pleomorphism, along with occasional swollen chondrocytes, due to cytoplasmic vacuolization. Rare foci of mitotic figures are also seen.

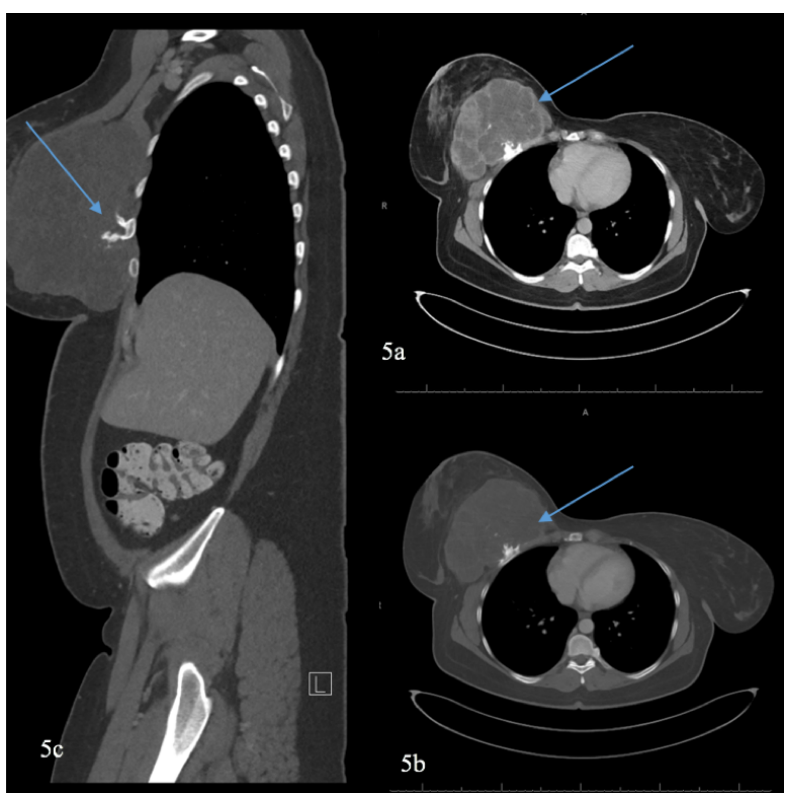

Figure 5. A) Post contrast axial CT image of the chest, soft tissue window. Demonstrates a multilobulated, septated lesion with central scattered punctate irregular mineralizations arising from the anterolateral segment of the right fifth rib (blue arrow), measuring $15 \mathrm{x}$ $14.5 \times 10 \mathrm{~cm}$. B) Post contrast axial CT image of the chest, bone window. Demonstrates the same lesion, consistent with a primary chondrosarcoma. C) Sagittal reformatted CT image. Demonstrates the mass arising from the anterior surface of the rib. Technique. Multiple contiguous axial images of the chest were obtained following intravenous administration of IV and oral contrast, $150 \mathrm{~mL}$ lopamidol $61 \%$ IV solution. Sagittal and coronal reformatted images were also obtained as needed. 
Table 1. Differential diagnosis for primary chest wall chondrosarcoma, highlighting newly described mammographic findings.

\begin{tabular}{|c|c|c|c|c|c|}
\hline $\begin{array}{l}\text { Differential } \\
\text { Diagnosis }\end{array}$ & Mammography & Plain radiograph & Chest CT & Chest MRI & Ultrasound \\
\hline Chondrosarcoma & $\begin{array}{l}\text { Retropectoral mass with } \\
\text { central ring and arc type } \\
\text { calcifications }\end{array}$ & $\begin{array}{l}\text { - Endosteal scalloping } \\
\text { - Intralesional calcifications } \\
\text { - Cortical remodeling and } \\
\text { periosteal reactions }\end{array}$ & $\begin{array}{l}\text { - Ring and arc chondroid } \\
\text { matrix mineralization } \\
\text { - Soft-tissue extension, lytic } \\
\text { patterns, endosteal scalloping, } \\
\text { punctate or irregular } \\
\text { calcifications are consistent } \\
\text { with high grade tumors }\end{array}$ & $\begin{array}{l}\text { - Heterogeneous mass } \\
\text { - Indeterminate signal on } \\
\text { T1WI with extensive septal } \\
\text { enhancement } \\
\text { - Hyperintense signal on } \\
\text { T2WI }\end{array}$ & $\begin{array}{l}\text { Retropectoral mass with } \\
\text { multiple nonvascular cystic } \\
\text { areas }\end{array}$ \\
\hline Osteosarcoma & N/A & $\begin{array}{l}\text { - Aggressive periosteal } \\
\text { reaction (sunburst type, } \\
\text { Codman's triangle) } \\
\text { - Medullary and cortical bone } \\
\text { destruction } \\
\text { - Calcified matrix }\end{array}$ & Same as plain radiograph & $\begin{array}{l}\text { - Low signal on T1WI } \\
\text { - High signal on T2WI }\end{array}$ & N/A \\
\hline Enchondroma & N/A & $\begin{array}{l}\text { - Sharply defined margins } \\
\text { with no cortical remodeling } \\
\text { - No periosteal reaction } \\
\text { - Chondroid ring and arc } \\
\text { calcifications }\end{array}$ & Same as plain radiograph & $\begin{array}{l}\text { - Well circumscribed } \\
\text { lobulated mass } \\
\text { - Low signal on T1WI } \\
\text { - High signal on T2WI }\end{array}$ & N/A \\
\hline Osteochondroma & N/A & $\begin{array}{l}\text { - Cartilaginous cap with ring } \\
\text { and arc calcification } \\
\text { - Broadening of the bone } \\
\text { metaphysis } \\
\text { - Sessile or pedunculated }\end{array}$ & $\begin{array}{l}\text { Sessile or pedunculated } \\
\text { lesion with rings and arcs of } \\
\text { calcifications without bony } \\
\text { destruction or soft tissue } \\
\text { expansion }\end{array}$ & $\begin{array}{l}\text { - Low signal on T1WI } \\
\text { - High signal on T2WI }\end{array}$ & $\begin{array}{l}\text { Cartilaginous cap } \\
\text { characterized by a } \\
\text { hypoechoic region defined } \\
\text { by muscle/fat superiorly and } \\
\text { bone inferiorly }\end{array}$ \\
\hline
\end{tabular}

Table 2. Summary table for primary chest wall chondrosarcoma

\begin{tabular}{|c|c|}
\hline Etiology & $\begin{array}{l}\text { The majority of primary chest wall chondrosarcomas arise de novo. However, approximately } 10 \% \text { of the tumors are thought to be radiation- } \\
\text { induced after treatment of other malignancies. Secondary chondrosarcomas can develop in pre-existing benign lesions. }\end{array}$ \\
\hline Incidence & $\begin{array}{l}\text { The incidence of a conventional primary chondrosarcoma is less than } 0.5 \text { cases per million people per year. However, it is the most frequent } \\
\text { malignant tumor of the thoracic cage. }\end{array}$ \\
\hline Gender Ratio & Primary chondrosarcomas have a slight predilection for males. \\
\hline Age Predilection & Primary chondrosarcomas typically present in the fourth and fifth decades of life. \\
\hline Risk Factors & $\begin{array}{l}\text { Risk factors that have been identified with developing primary chest wall tumors include prior trauma and radiation treatment for other } \\
\text { malignancies, including breast cancer or lymphoma. }\end{array}$ \\
\hline Treatment & Surgical resection is the most effective treatment, as primary chest wall chondrosarcomas are resistant to chemotherapy and radiotherapy. \\
\hline Prognosis & $\begin{array}{l}\text { Prognosis and survival rate are contingent upon histologic grading, which is based upon tumor mitotic rate, cellularity, and nuclear size. The five- } \\
\text { year survival rate for grade } 1 \text { tumors is } 90 \% \text {, grade } 2 \text { tumors is } 81 \% \text { and grade } 3 \text { tumors is } 43 \% \text {. The ten year survival rates are } 83 \%, 64 \% \text {, and } \\
29 \% \text { for grades } 1,2 \text {, and } 3 \text { tumors, respectively. }\end{array}$ \\
\hline Image Findings & $\begin{array}{l}\text { When presenting in a female, primary chest wall chondrosarcoma may be demonstrated on mammogram as a retropectoral mass with central } \\
\text { calcifications in an arc and ring configuration. Ultrasound will reveal a cystic and solid nonvascular mass. CT imaging will demonstrate a } \\
\text { multilobulated septated mass with several central scattered punctate mineralizations. T2 MRI will show a lobular hyperintense mass. Postcontrast } \\
\text { MRI images will demonstrate septal enhancement. }\end{array}$ \\
\hline
\end{tabular}

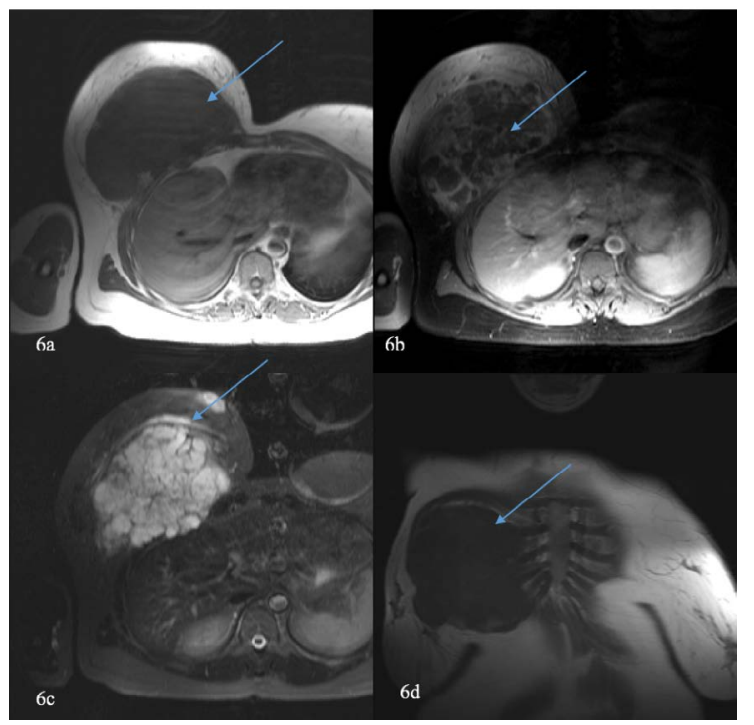

Figure 6. A) Non-contrast axial T1 weighted MRI. Demonstrates a hypointense lobulated mass. B) Post-contrast axial T1 weighted fat saturated MRI image. Demonstrates extensive septal enhancement (blue arrow), consistent with chondroid matrix. C) Axial T2 weighted fat saturated MRI image. Demonstrates a large lobular hyperintense mass (blue arrow). D) Non-contrast coronal T1 weighted MRI image. Demonstrates the large mass which measured 15.1 x 9.7 x $15.7 \mathrm{~cm}$ Technique. Multiplanar multisequence MRI of the chest wall, with attention to the right chest wall mass, was performed with and without contrast with $\mathrm{T} 1, \mathrm{~T} 2$, proton density and post contrast $\mathrm{T} 1$ weighted sequences as per tumor protocol. 
accounting for $8 \%$ of all cases. They typically arise at the costochondral junction of the anterior portion of the rib [6].

Chondrosarcomas present radiographically with cartilaginous calcifications or scalloping [8]. Both benign and malignant lesions are characterized by "arc and ring" calcifications. Radiographic features that point to a malignant origin include lobulations, cortical destruction, size greater than $5 \mathrm{~cm}$, and tumor location in the axial skeleton [2,9]. On CT, chondrosarcoma is characterized by ring and arc chondroid matrix mineralization. Features such as soft-tissue extension, lytic patterns, endosteal scalloping, amorphous, irregular, punctate or irregular calcifications scattered within the lesion $[6,10,11]$ are consistent with high grade tumors. On MRI, chondrosarcoma appears as a heterogeneous mass with intermediate signal on T1-weighted sequences and hyperintense signal on T2-weighted sequences [12]. In our case, given the classic ring and arc type internal calcifications seen on mammography, the leading diagnosis was chondrosarcoma which was confirmed via ultrasound guided core needle biopsy.

\section{Differential diagnoses}

Chondrosarcoma should be included in the differential diagnosis for patients who present with an enlarging painless palpable breast mass that has retropectoral central ring and arc type calcifications on initial imaging, including mammography. These radiographic findings can be nonspecific when initially noted, but consideration should be given to a primary chondrosarcoma when presenting as an enlarging firm immobile mass. The patient's age and tumor location can help differentiate chondrosarcoma from other differential considerations. The main differential diagnoses include but are not limited to osteosarcoma, enchondroma, and osteochondroma. Further considerations before pathologic correlation included chest wall lymphoma, multiple myeloma and fibromatosis.

\section{Osteosarcoma}

Osteosarcomas are malignant bone forming tumors that, like chondrosarcomas, present with soft-tissue mass or swelling. Unlike chondrosarcomas, they typically present before the age of 20 , as bone growth is greatest in adolescence. They tend to occur in the metaphysis of long bones, with up to $60 \%$ occurring at the knee. Like chondrosarcomas, osteosarcomas demonstrate ring and arc calcifications, a soft tissue mass, and aggressive periosteal reactions on plain radiograph. However, a sunburst periosteal reaction is more typical for osteosarcoma.

\section{Enchondroma}

Enchondromas are benign bone lesions that are typically diagnosed in childhood and adolescence. Unlike chondrosarcomas, enchondromas are usually incidental findings on imaging and are asymptomatic. They have a predilection for the medullary cavity of tubular bones and up to $50 \%$ of them occur in the hands and feet. Very rarely, they can transform into a malignant low-grade chondrosarcoma. Like chondrosarcomas, enchondromas are characterized by chondroid ring and arc calcifications on imaging. However, enchondromas exhibit benign features: a well circumscribed lobulated mass with sharply defined margins and no cortical remodeling or periosteal reactions.

\section{Osteochondroma}

Osteochondromas are benign bone tumors that typically develop during childhood, although they can present at any age. They are either found incidentally on imaging or can present with a palpable mass or mechanical impingement on nerves or vasculature due to size. Osteochondromas typically arise in the appendicular skeleton. Like other differentials for chondrosarcoma, osteochondroma is characterized by ring and arc calcifications on plain radiographs. There is no bony destruction or soft tissue expansion, helping to differentiate it with a chondrosarcoma. These tumors can be pedunculated and can broaden the bone metaphysis from which they originate.

\section{Treatment and prognosis}

Surgical resection is the most effective treatment as chondrosarcoma grows slowly and is relatively resistant to chemotherapy and radiotherapy [1,3,13-15]. Prognosis and survival rate are contingent upon histologic grading, which is based upon tumor mitotic rate, cellularity, and nuclear size. The five-year survival rate for grade 1 tumors is $90 \%$, grade 2 tumors is $81 \%$ and grade 3 tumors is $43 \%$. The ten-year survival rates are $83 \%, 64 \%$, and $29 \%$ for grades 1,2 , and 3 tumors, respectively. Local recurrence is highly dependent on surgical margins $[13,15,16]$. Costal chondrosarcoma is a challenge to treat, as wide resection with resection of multiple ribs can result in flail chest [17].

\section{Conclusion}

Primary chondrosarcoma of the chest wall differential diagnosis presenting with an enlarging firm, immobile painless deeply seated breast mass. Mammogram will demonstrate a retropectoral mass with central calcifications. CT and T2-weighted MRI will demonstrate a mineralized septated lesion and a lobular hyperintense mass, respectively.

\section{Acknowledgements}

No additional acknowledgements.

\section{References}

1. Gelderblom H, Hogendoorn PC, Dijkstra SD, van Rijswijk CS, Krol AD, et al. (2008) The clinical approach towards chondrosarcoma. Oncologist 13: 320-329. [Crossref]

2. Murphey M, Flemming D, Boyea S, et al. (1998) Enchondroma versus chondrosarcoma in the appendicular skeleton: differentiating features. Continuing Education. 18: 1213-1237.

3. Burt M1, Fulton M, Wessner-Dunlap S, Karpeh M, Huvos AG, et al. (1992) Primary bony and cartilaginous sarcomas of chest wall: results of therapy. Ann Thorac Surg 54: 226-232. [Crossref]

4. Dorfman HD, Czerniak B (1995) Bone cancers. Cancer 75: 203-210. [Crossref]

5. Murphey M, Walker E, Wilson A, et al. (2003) Imaging of primary chondrosarcoma: radiologic-pathologic correlation. RadioGraphics. 23: 1245-1278.

6. Thomas M, Shen KR (2017) Primary Tumors of the Osseous Chest Wall and Their Management. Thorac Surg Clin 27: 181-193. [Crossref]

7. Marruli G, Duranti L, Cardillo G, et al. (2014) Primary chest wall chondrosarcomas results of surgical resection and analysis of prognostic factors. European Journal of Cardio-Thoracic Surgery. 45: 194-201.

8. Meyer CA, White CS (1998) Cartilaginous disorders of the chest. Radiographics 18 1109-1123. [Crossref]

9. O'Sullivan P, O'Dwyer H, Flint J, Munk PL, Muller NL (2007) Malignant chest wall neoplasms of bone and cartilage: a pictorial review of CT and MR findings. Br J Radiol 80: 678-684. [Crossref]

10. Widhe B, and Bauer H (2009) Surgical treatment is decisive for outcome in chondrosarcoma of the chest wall: a population-based Scandinavian Sarcoma Group study of 106 patients. General Thoracic Surgery. 137: 610-614.

11. Murphey MD, Robbin MR, McRae GA, Flemming DJ, Temple HT, et al. (1997) The many faces of osteosarcoma. Radiographics 17: 1205-1231. [Crossref]

12. Murphey MD, Flemming DJ, Boyea SR, et al. (1998) Enchondroma versus chondrosarcoma in the appendicular skeleton: differentiating features. RadioGraphics. 18: 1213-1237.

13. Murphey MD, Choi JJ, Kransdorf MJ, Flemming DJ, Gannon FH (2000) Imaging of osteochondroma: variants and complications with radiologic-pathologic correlation. Radiographics 20: 1407-1434. [Crossref] 
14. Briccoli A, De Paolis M, Campanacci L, Mercuri M, Bertoni F, et al. (2002) Chondrosarcoma of the chest wall: a clinical analysis. Surg Today 32: 291-296. [Crossref]

15. McAfee MK, Pairolero PC, Bergstralh EJ, Piehler JM, Unni KK, et al. (1985) Chondrosarcoma of the chest wall: factors affecting survival. Ann Thorac Surg 40: 535-541. [Crossref]
16. Marruli G, Duranti L, Cardillo G, et al. (2014) Primary chest wall chondrosarcomas: results of surgical resection and analysis of prognostic factors. European Journal of Cardio-Thoracic Surgery. 45: 194-201.

17. Evans HL, Ayala AG, Romsdahl MM (1977) Prognostic factors in chondrosarcoma of bone: a clinicopathologic analysis with emphasis on histologic grading. Cancer 40 : 818-831. [Crossref]

Copyright: (C2017 Klevos GA. This is an open-access article distributed under the terms of the Creative Commons Attribution License, which permits unrestricted use, distribution, and reproduction in any medium, provided the original author and source are credited. 